\title{
Single Step In Situ Synthesis and Optical Properties of Polyaniline/ZnO Nanocomposites
}

\author{
Deepali Sharma, ${ }^{1}$ B. S. Kaith, ${ }^{2}$ and Jaspreet Rajput ${ }^{2}$ \\ ${ }^{1}$ Department of Chemistry, Sant Longowal Institute of Engineering and Technology, Longowal, Sangrur, Punjab 148106, India \\ ${ }^{2}$ Department of Chemistry, Dr. B. R. Ambedkar National Institute of Technology, Jalandhar, Punjab 144 011, India \\ Correspondence should be addressed to Deepali Sharma; dpschem@gmail.com
}

Received 15 August 2013; Accepted 3 October 2013; Published 2 January 2014

Academic Editors: S. Anandan and Y. Chai

Copyright (c) 2014 Deepali Sharma et al. This is an open access article distributed under the Creative Commons Attribution License, which permits unrestricted use, distribution, and reproduction in any medium, provided the original work is properly cited.

\begin{abstract}
Polyaniline/ZnO nanocomposites were prepared by in situ oxidative polymerization of aniline monomer in the presence of different weight percentages of $\mathrm{ZnO}$ nanostructures. The steric stabilizer added to prevent the agglomeration of nanostructures in the polymer matrix was found to affect the final properties of the nanocomposite. $\mathrm{ZnO}$ nanostructures of various morphologies and sizes were prepared in the absence and presence of sodium lauryl sulphate (SLS) surfactant under different reaction conditions like in the presence of microwave radiation (microwave oven), under pressure (autoclave), under vacuum (vacuum oven), and at room temperature (ambient condition). The conductivity of these synthesized nanocomposites was evaluated using two-probe method and the effect of concentration of $\mathrm{ZnO}$ nanostructures on conductivity was observed. X-ray diffraction (XRD), scanning electron microscopy (SEM), transmission electron microscopy (TEM), Fourier transform infrared spectroscopy (FTIR), and UV-visible (UV-VIS) spectroscopy techniques were used to characterize nanocomposites. The optical energy band gap of the nanocomposites was calculated from absorption spectra and ranged between 1.5 and $3.21 \mathrm{eV}$. The reported values depicted the blue shift in nanocomposites as compared to the band gap energies of synthesized $\mathrm{ZnO}$ nanostructures. The present work focuses on the one-step synthesis and potential use of PANI/ZnO nanocomposite in molecular electronics as well as in optical devices.
\end{abstract}

\section{Introduction}

With the advent of advancement in the field of nanoscience and nanotechnology in the recent years, nanocomposites of different metals and conducting polymers or metal oxidepolymer have become an important class of materials. These materials find potential applications as sensors, UV detectors, catalysts, biosensors, and piezoelectronic materials [1-4]. As with conventional composites, the properties of nanocomposites can display synergistic improvements over those of the component phases individually. However, by reducing the physical dimension(s) of the phase(s) down to the nanometer length scale, unusual and often enhanced properties can be realized. An important microstructural feature of nanocomposites is their large ratio of interphase surface area to volume. The nanocomposites differ from pure polymers and inorganic metal oxide nanoparticles in some physical and chemical properties.
Among various metal oxide nanoparticles, $\mathrm{ZnO}$ is a key technological and multifunctional inorganic material with unaccountable applications such as sensors, optical, electronic, magnetic, catalytic and detection of biological molecules [5-11]. It is a versatile functional material that has a diverse group of growth morphologies, such as nanocombs, nanorings, nanohelixes/nanosprings, nanobelts, nanobeads, nanowires, and nanocages [12-17]. These unique nanostructures unambiguously demonstrate that $\mathrm{ZnO}$ has the richest family of nanostructures among all materials, both in structures and in properties. It has a direct band gap of $3.37 \mathrm{eV}$ and high exciton binding energy of $60 \mathrm{meV}$ at room temperature [18-20].

Among different conducting polymers, polyaniline (PANI) is one of the most widely studied conducting polymers over the past 50 years and thus has received great attention due to its ease of synthesis, environmental stability, electrical, optical and electrochemical properties, and simple 
doping/dedoping chemistry [21]. It was first synthesized in 1862 and has been studied since 1980s [22]. Polyaniline can exist in various oxidation states. The three major oxidation states are leucoemeraldine (white/clear and colourless), emeraldine (green for emeraldine salt and blue for emeraldine base), and pernigraniline (blue/violet). Among the above three oxidation states, the fully reduced state is leucoemeraldine with $n=1, m=0$. Pernigraniline is the fully oxidized state with $n=0, m=1$. The emeraldine $(n=m=$ $0.5)$ form of polyaniline is also referred to as emeraldine base (EB) and is neutral. On doping, it changes to emeraldine salt (ES) with the imine nitrogens protonated by an acid. Emeraldine base (EB) is considered to be the most useful form of aniline due to its high stability at room temperature. On doping emeraldine base (EB) with nonoxidising protonic acids such as $\mathrm{HCl}, \mathrm{H}_{2} \mathrm{SO}_{4}$, or organic acids (p-toluene sulfonic acid), it is converted into emeraldine salt (ES) form which is electrically conducting [23, 24]. Polyaniline can be easily synthesized either chemically or electrochemically from acidic aqueous solutions [25]. The most common synthesis of polyaniline is by oxidative polymerization with ammonium peroxodisulfate as an oxidant [26].

Various methods have been reported for the synthesis of nanocomposites. The most common method involves the oxidative polymerization of aniline. In this, aqueous aniline is dissolved in $1 \mathrm{M} \mathrm{HCl}$ regulating the temperature at $0^{\circ} \mathrm{C}$ followed by the addition of oxidant (ammonium peroxydisulfate). The use of surfactants assures a good dispersion of metal oxide nanoparticles in the polymer along with embedding them in the growing polymer during polymerization $[27,28]$. Chemical methods based on the in situ sol gel polymerization method allow single-step synthesis of polymer inorganic nanocomposites in the presence of polymer or monomer [29]. It is possible to manipulate the organic or inorganic interfacial interactions at various molecular and nanometer length scales using this method, resulting in homogeneous polymer inorganic nanocomposites structures and thus, overcoming the problem of nanoparticle agglomeration [3032].

In the present work, polyaniline (PANI)/ZnO nanocomposites have been synthesized by a single-step process by loading different weights of $\mathrm{ZnO}$ nanostructures synthesized in the presence and absence of sodium lauryl surfactant (SLS) and characterized for their structural and optical properties. Further, the conductivity of the nanocomposites has been evaluated using two-probe method.

\section{Experimental}

\subsection{Materials and Methods}

2.1.1. Chemicals. $\mathrm{ZnSO}_{4} \cdot 7 \mathrm{H}_{2} \mathrm{O}$ (SdFine), $\mathrm{NaOH}$ (SdFine), aniline (SdFine), $\mathrm{HCl}$ (35\% GR), ammonium peroxidisulfate (MERCK), sodium lauryl sulphate (SdFine), methanol (MERCK, 99\%), and as-synthesized $\mathrm{ZnO}$ nanoparticles were used. Double-distilled water was employed.
2.1.2. Equipments. Microwave (LG Model no. MB394AA), vacuum oven (Navyug India Q-5247), autoclave (LABCOIndia ISO-9001), UV-visible spectrophotometer (Systronics Double Beam UV-Vis Spectrophotometer: 2201), vacuum filter (HARCO), and ELIX 3Millipore were used.

\subsection{Synthesis of $\mathrm{ZnO}$ Nanostructures}

2.2.1. Surfactant Free Microwave Synthesis. Initially, $50 \mathrm{~mL}$ of zinc sulphate heptahydrate $\left(\mathrm{ZnSO}_{4} \cdot 7 \mathrm{H}_{2} \mathrm{O}\right)$ and $50 \mathrm{~mL}$ of sodium hydroxide $(\mathrm{NaOH})$ solutions in 1:4 molar ratio were prepared and were mixed together in a reaction flask, followed by vigorous stirring for $15 \mathrm{~min}$ at ambient temperature. The reaction was further carried out under the influence of microwave radiations by placing the reaction flask in the microwave for $2 \mathrm{~min}$. The reaction flask was cooled to room temperature and the product was filtered and washed with deionized water followed by drying at $40^{\circ} \mathrm{C}$.

\subsubsection{Surfactant Assisted Synthesis under Different Reaction} Conditions. In a typical procedure, $100 \mathrm{~mL}$ of zinc sulphate heptahydrate $\left(\mathrm{ZnSO}_{4} \cdot 7 \mathrm{H}_{2} \mathrm{O}\right)$ solution and $100 \mathrm{~mL}$ of sodium lauryl sulphate (surfactant) solution were mixed with $100 \mathrm{~mL}$ of sodium hydroxide $(\mathrm{NaOH})$ solution in 1:0.4:4 molar ratio and stirred vigorously for $15 \mathrm{~min}$. This was followed by exposure to microwave irradiation for $2 \mathrm{~min}$. The white product obtained was washed 5-6 times with distilled water and ethanol and dried at $40^{\circ} \mathrm{C}$. Similar procedure was followed to obtain the product under other reaction conditions like under pressure (UP, pressure: 5 psi), under vacuum (UV, vacuum: $160 \mathrm{mmHg}$ ), and at room temperature (RT).

2.3. Synthesis of Polyaniline (PANI). $0.25 \mathrm{M}$ aniline was added to the mixture of $0.175 \mathrm{M}$ sodium lauryl sulphate (SLS) and $0.75 \mathrm{M} \mathrm{HCl}$ at $0^{\circ} \mathrm{C}$. The temperature of the ice bath was maintained at $0 \pm 1^{\circ} \mathrm{C}$. The resulting mixture was stirred for $1 \mathrm{~h}$ maintaining the above temperature. It was followed by the addition of $1.2 \mathrm{~g}$ of ammonium persulfate (APS) dissolved in $20 \mathrm{~mL}$ distilled water. The resulting mixture was stirred vigorously for $1 \mathrm{~h}$. Polyaniline was precipitated with methanol. The green coloured product was obtained by vacuum filtration and washed several times with double distilled water and dried at $45^{\circ} \mathrm{C}$ for $8 \mathrm{~h}$. The dried and fine powdered green coloured product was pressed in the form of pellet using hydraulic press.

\subsection{Preparation of Polyaniline (PANI)/ZnO Nanocomposites.} To prepare nanocomposite, $0.25 \mathrm{M}$ aniline was added to $0.175 \mathrm{M}$ sodium lauryl sulphate (SLS) and $0.75 \mathrm{M} \mathrm{HCl}$ at $0^{\circ} \mathrm{C}$. The temperature of the ice bath was maintained at $0 \pm 1^{\circ} \mathrm{C}$. The resulting reaction mixture was stirred for $1 \mathrm{~h}$ maintaining the above temperature. This was followed by the addition of different percentages of $\mathrm{ZnO}$ nanostructures synthesized in the absence and presence of sodium lauryl sulphate (SLS) surfactant under different reaction conditions. $1.2 \mathrm{~g}$ of ammonium persulfate (APS) dissolved in $20 \mathrm{~mL}$ distilled water was added slowly to the reaction mixture with constant stirring. The reaction mixture turned viscous and green and was 
<smiles>[NH3+]OS(=O)(=O)OOS(=O)(=O)O[NH3+]</smiles>
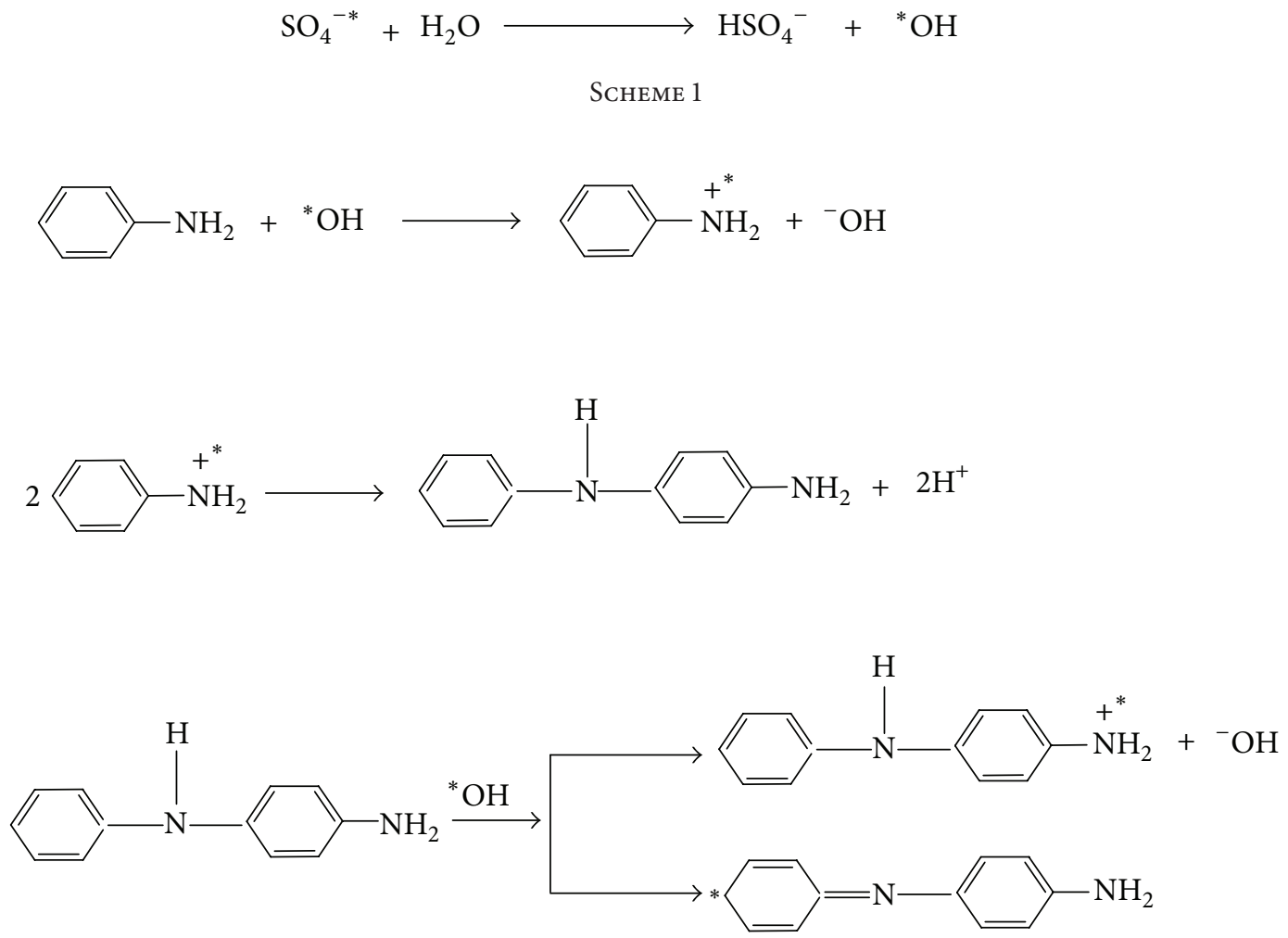

SCHEME 2

stirred for $1 \mathrm{~h}$. The nanocomposite formed was precipitated using methanol. Finally, the green coloured product was obtained by vacuum filtration and washed several times with double distilled water and dried at $45^{\circ} \mathrm{C}$ for $8 \mathrm{~h}$. The dried and fine powdered green coloured product was pressed in the form of pellets using hydraulic press and characterized using XRD, SEM, TEM, FTIR, and UV-Vis spectrophotometric techniques.

2.5. Conductivity Measurement of Polyaniline (PANI)/ZnO Nanocomposite. The conductivity measurement of the dried pellets was carried out using two-probe method. All the measurements were done at room temperature $\left(30^{\circ} \mathrm{C}\right)$ at an applied voltage of 20 volts. Measurements were taken after 15 min of applying voltage.

\section{Results and Discussion}

The polymerization of aniline was carried out in the aqueous solution in the presence of sodium lauryl sulphate and hydrochloric acid at low temperature $\left(0 \pm 1^{\circ} \mathrm{C}\right)$. Intial stages of polymerization resulted in the formation of aniline dodecylsulphonic acid and aniline hydrochloric acid which enhanced the solubility of polymer and provided a conducting polymer structure. As soon as ammonium persulfate (APS) was added, the colour of the reaction mixture changed from white to green and finally to dark green colouration. The different weight percentages of $\mathrm{ZnO}$ nanostructures synthesized under different reaction conditions were added prior to adding APS. Thus, PANI/ZnO nanocomposite was formed during the polymerization process.

Polymerization of the aniline takes place through (Scheme 1) proposed mechanism.

The * $\mathrm{OH}$ generated from APS resulted in the formation of aniline cation radical which initiated the polymerization process.

Initiation. See Scheme 2.

Propagation. See Scheme 3.

3.1. Characterization. Characterization was carried out with X-ray diffractometer (PANalytical), Scanning electron 
<smiles>Nc1ccccc1</smiles><smiles>CCC</smiles><smiles>Nc1ccc(Nc2ccc(Nc3ccccc3)cc2)cc1</smiles><smiles>Nc1ccc(Nc2ccc(Nc3ccccc3)cc2)cc1</smiles>

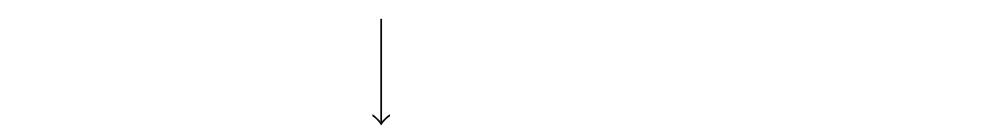<smiles>[NH3+]c1ccc(Nc2ccc(Nc3ccccc3)cc2)cc1</smiles><smiles>Nc1ccc(N=C2C=C[C+]([NH3+])C=C2)cc1</smiles><smiles>CCCC</smiles>

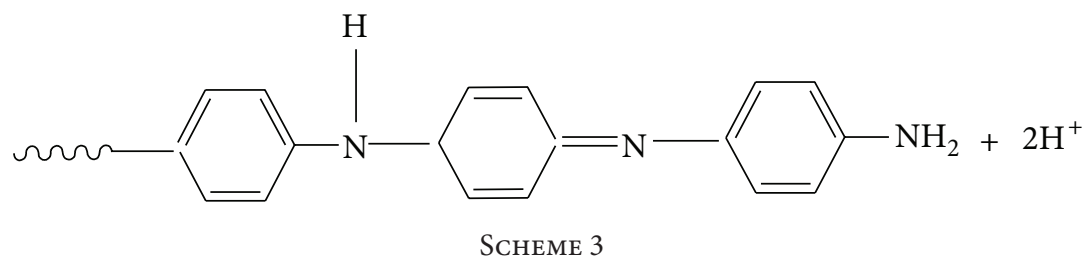

microscope (JSM-6610LV), transmission electron microscope (Technai $\mathrm{G}^{2} \mathrm{X}$ 9900), Fourier-transform infrared spectrometer (FTIR, Model 1600 Perkin-Elmer), and UV-visible spectrophotometer (SYSTRONICS DOUBLE BEAM UV-VIS Spectrophotometer: 2201).
3.1.1. X-Ray Diffraction (XRD) Studies. Figure 1(a) represents the XRD pattern of polyaniline. A maximum peak at $2 \theta=$ $20.9^{\circ}$ can be assigned to the scattering from the polyaniline chains at interplanar spacing [33]. From the XRD pattern it was observed that the synthesized polyaniline was partially 


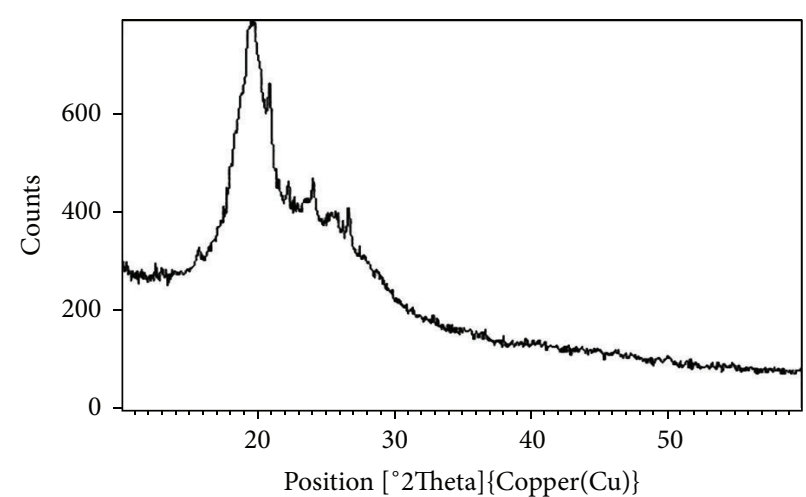

(a)

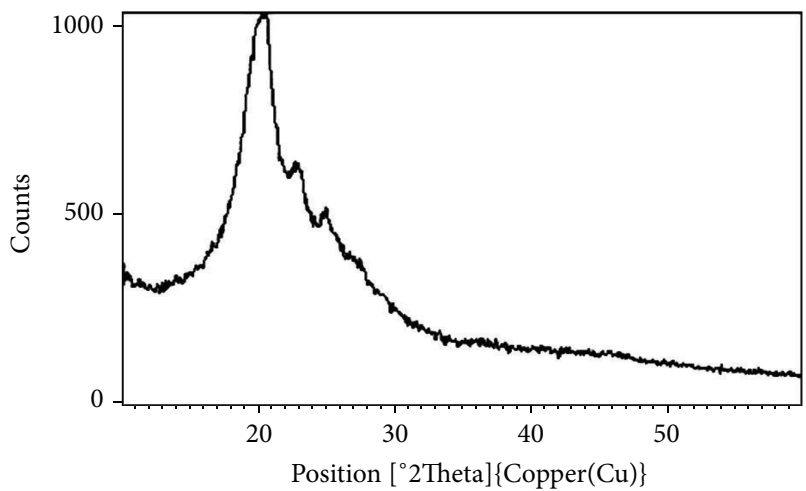

(c)

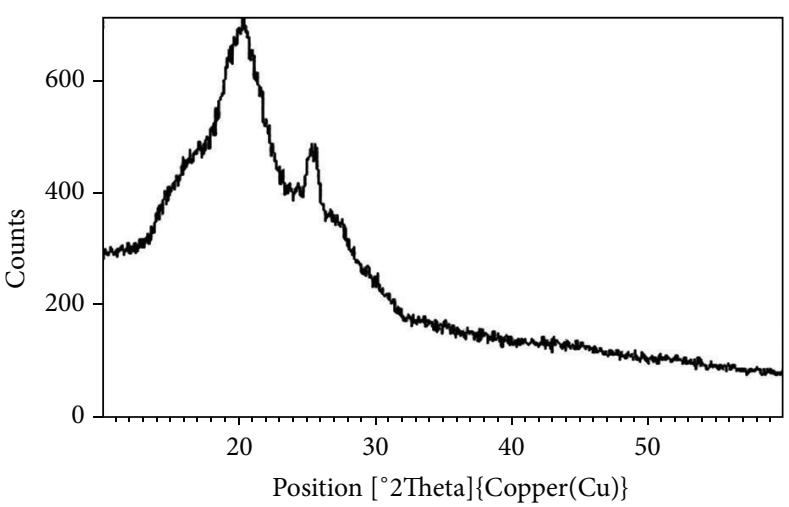

(e)

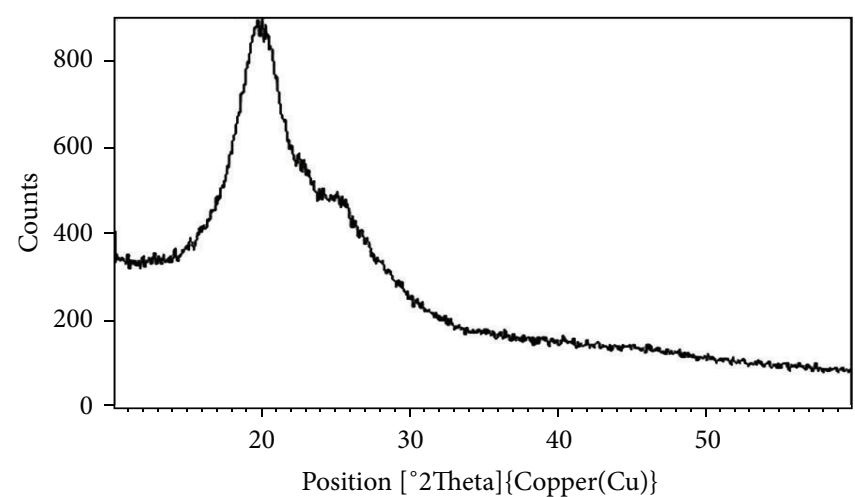

(b)

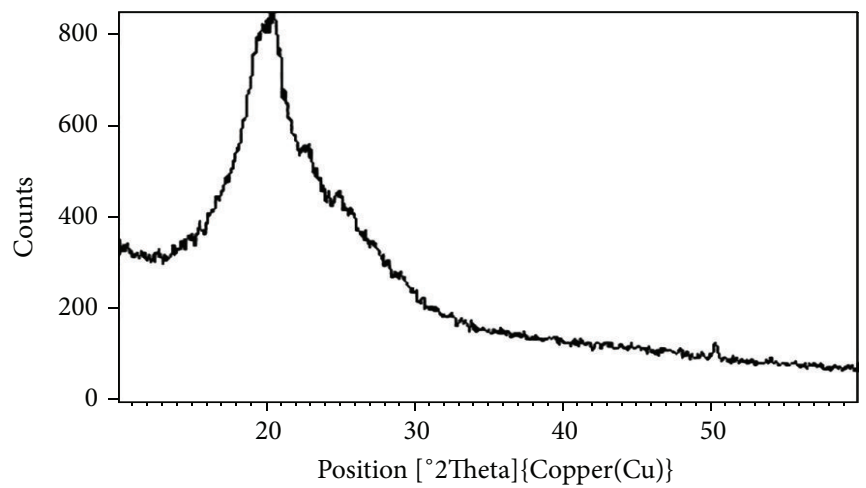

(d)

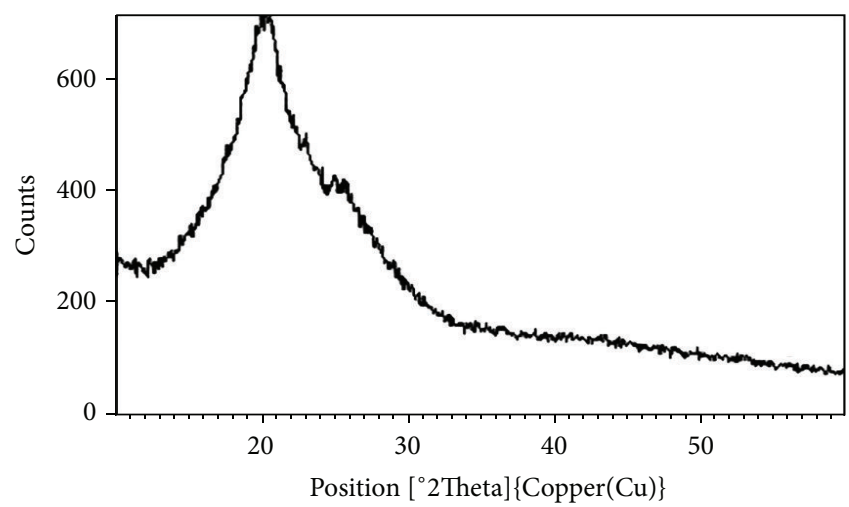

(f)

Figure 1: XRD Spectra of (a) polyaniline (PANI), (b) PANI/60\% ZnO-SF-MW, (c) PANI/60\% ZnO-SLS-MW, (d) PANI/40\% ZnO-SLS-UP, (e) PANI/60\% ZnO-SLS-UV, and (f) PANI/40\% ZnO-SLS-RT nanocomposites.

crystalline, that is, amorphous in nature. Figures 1(b), 1(c), $1(\mathrm{~d}), 1(\mathrm{e})$, and $1(\mathrm{f})$ show the XRD patterns of PANI/ZnO nanocomposites. In Figure $1(\mathrm{~b}), 60 \% \mathrm{ZnO}$ nanoparticles of spherical morphology synthesized in the absence of surfactant have been incorporated into the polymer (PANI) matrix. Figure 1(c) shows the incorporation of $60 \% \mathrm{ZnO}$ nanoparticles synthesized using sodium lauryl sulphate (SLS) surfactant under microwave condition. In Figure 1(e), a sharp peak around $2 \theta=25.6^{\circ}$ appeared in the nanocomposite. A normal $\mathrm{ZnO}$ peak appears around $2 \theta=30.0^{\circ}$. A shift in the peak was observed to lower angle. It was inferred from the pattern that $\mathrm{ZnO}$ nanostructures interacted with the chains of polyaniline. Figures 1(d) and 1(f) show the physical interaction of the $40 \% \mathrm{ZnO}$ nanostructures synthesized using SLS under pressure and at room temperature, with the polymer chains.

The coherence length (CL) of PANI and PANI/ZnO nanocomposites was measured using Scherrer's equation:

$$
\mathrm{CL}=\frac{\lambda k}{\beta \cos \theta},
$$

where $\lambda$ is wavelength (1.54 $\AA$ ); $k$ is the constant (0.9); $\beta=$ full width at half maxima (FWHM); $\theta$ is the wide angle XRD peak position. 
TABLE 1: Measurement of coherence length of PANI/ZnO nanocomposites.

\begin{tabular}{|c|c|c|c|c|c|}
\hline Sample & Position [ $\left.{ }^{\circ} 2 \mathrm{Th}\right]$ & FWHM [ $\left.{ }^{\circ} 2 \mathrm{Th}\right]$ & d-spacing $(\AA)$ & Coherence length (nm) & $\sigma_{\mathrm{dc}}, S \mathrm{~cm}^{-1}$ \\
\hline PANI & 19.6234 & 0.9368 & 4.52399 & 16.9 & $4.5 \times 10^{-14}$ \\
\hline PANI/60\% ZnO-SF-MW & 20.4360 & 0.7220 & 4.23657 & 21.7 & $1.82 \times 10^{-13}$ \\
\hline PANI/60\% ZnO-SLS-MW & 23.0113 & 0.6691 & 3.86503 & 23.6 & $4.2 \times 10^{-13}$ \\
\hline PANI/40\% ZnO-SLS-UP & 20.4430 & 0.9116 & 4.34083 & 17.3 & $1.15 \times 10^{-13}$ \\
\hline PANI/60\% ZnO-SLS-UV & 25.6006 & 0.9183 & 3.47681 & 17.5 & $2.9 \times 10^{-13}$ \\
\hline $\mathrm{PANI} / 40 \% \mathrm{ZnO}-\mathrm{SLS}-\mathrm{RT}$ & 20.6597 & 0.8160 & 4.29579 & 19.2 & $2.07 \times 10^{-13}$ \\
\hline
\end{tabular}

The data obtained after applying Scherrer's equation has been given in Table 1 .

It has been observed that the coherence length (CL) of PANI/ZnO nanocomposites was higher in comparison to that of PANI (Table 1). Thus, higher coherence length indicated higher crystallinity and crystalline coherence which further contributed to higher conductivity of nanocomposites as compared to PANI $[34,35]$.

In the case of nanocomposites, the calculated coherence length depends on how the $\mathrm{ZnO}$ nanoparticles are embedded in the polymer matrix and are linked to the polymeric chains. In the present case, $\mathrm{ZnO}$-SLS-MW was reported to have high coherence length value as the nanorods linked well with the polymeric chains (Figure 2(c)). It has been observed from the SEM image (Figure 2(b)) that the spherical shaped particles dispersed well within the polymer matrix. Due to formation of nanoneedles of length $120 \mathrm{~nm}$ in the case of ZnO-SLSRT, they lead to good coherence value. The nanoplates formed in the case of ZnO-SLS-UV linked with the polymer chains but not in ordered manner. Similarly, nanoflowers formed via ZnO-SLS-UP seemed to overlap while linking with the polymer chains (Figure 2(d)). Thus, it could be concluded that coherence length is much dependent on how the nanoparticles are arranged in the polymer matrix rather than being dependent on morphology, size, and surface area.

3.1.2. Scanning Electron Microscopy (SEM) Studies. Figure 2(a) shows the surface morphology of the as-synthesized polyaniline. Figures 2(b)-2(f) are SEM images of the nanocomposite with varying percentage of $\mathrm{ZnO}$ nanostructures. It is evident from the SEM micrographs that the morphology of polyaniline has changed with the introduction of $\mathrm{ZnO}$ nanostructures of different morphologies. Figures 2(b) and 2(c) depict the uniform distribution of spherical and nanorod shaped $\mathrm{ZnO}$ into the polymer matrix, respectively. Figure 2(d) shows the incorporation of $\mathrm{ZnO}$ nanoflowers synthesized using SLS under pressure into the polymer matrix. Thus, it was interpreted that there was an effective interaction of $\mathrm{ZnO}$ nanostructures of varied morphology with polyaniline matrix.

3.1.3. Transmission Electron Microscopy (TEM) Studies. Figure 3(a) represents the TEM image of polyaniline network containing chains of the polymer whereas Figures 3(b)-3(e) represent the TEM images of PANI/ZnO nanocomposites containing different weight percentages of $\mathrm{ZnO}$ nanostructures synthesized via surfactant free and surfactant assisted methods. Figure $3(\mathrm{~b})$ is a TEM image of nanocomposite containing $60 \% \mathrm{ZnO}$ nanostructures synthesized using microwave method in the absence of surfactant, SLS. It has been observed that spherical $\mathrm{ZnO}$ nanoparticles in the size range of $20-25 \mathrm{~nm}$ have been dispersed in the polymer matrix. The dark spots in the TEM image are the nanoparticles. Figures 3(c) and 3(d) show the TEM images where $\mathrm{ZnO}$ nanostructures synthesized in the presence of SLS under microwave $(60 \% \mathrm{ZnO})$ and under pressure $(40 \% \mathrm{ZnO})$ have been well entrapped in the chains of polyaniline. Similarly, in the Figures 3(e) and 3(f), 60\% of $\mathrm{ZnO}$ nanostructures synthesized under vacuum (UV) and $40 \%$ of $\mathrm{ZnO}$ nanostructures synthesized at room temperature (RT) methods have been embedded in the matrix of polyaniline. Thus, Figures 3(b)-3(e) indicate that the surface of $\mathrm{ZnO}$ nanostructure has interaction with the PANI chains.

3.1.4. Fourier-Transform Infrared Spectroscopy (FTIR) Studies. Figure 4(a) illustrates the FTIR spectrum of polyaniline and Figures 4(b)-4(f) represent the FTIR spectra of nanocomposites, respectively. In Figure 4(a), the peaks at $1573.8 \mathrm{~cm}^{-1}$ and $1444.75 \mathrm{~cm}^{-1}$ correspond to $\mathrm{C}=\mathrm{C}$ stretching of quinoid and benzenoid rings, respectively. A sharp peak at $1288.58 \mathrm{~cm}^{-1}$ is characteristic of C-N stretching whereas a peak at $3240.40 \mathrm{~cm}^{-1}$ is of $\mathrm{N}-\mathrm{H}$ stretching mode. A peak at $3054.38 \mathrm{~cm}^{-1}$ belongs to $\mathrm{C}-\mathrm{H}$ stretching. $-\mathrm{CH}_{2}$ stretching occurs as a sharp peak at $2919.83 \mathrm{~cm}^{-1}$. The peaks at $517 \mathrm{~cm}^{-1}$ and $693.75 \mathrm{~cm}^{-1}$ correspond to $\mathrm{C}-\mathrm{Cl}$ stretching and $\mathrm{NH}_{2}$ wagging, respectively. In Figure $4(\mathrm{~b})$, there is a shift in the frequency of $\mathrm{C}=\mathrm{C}$ stretching of quinoid ring from $1573.8 \mathrm{~cm}^{-1}$ to $1570.38 \mathrm{~cm}^{-1}$. N-H stretching mode has moved to lower frequency $\left(3227.22 \mathrm{~cm}^{-1}\right)$ thereby decreasing the intensity of the peak. The peak present in Figure 4(a) at $517 \mathrm{~cm}^{-1}$ has vanished in Figure 4(b). This shows that there is bond formation between $\mathrm{ZnO}$ and amine group of polyaniline. Similarly, in Figure $4(\mathrm{c}), \mathrm{C}=\mathrm{C}$ stretching of quinoid ring occurs at $1571.02 \mathrm{~cm}^{-1}$ and $\mathrm{N}-\mathrm{H}$ stretching mode at $3209.81 \mathrm{~cm}^{-1}$. This shift in the frequencies confirms the formation of bond between $\mathrm{ZnO}$ and PANI and finally 


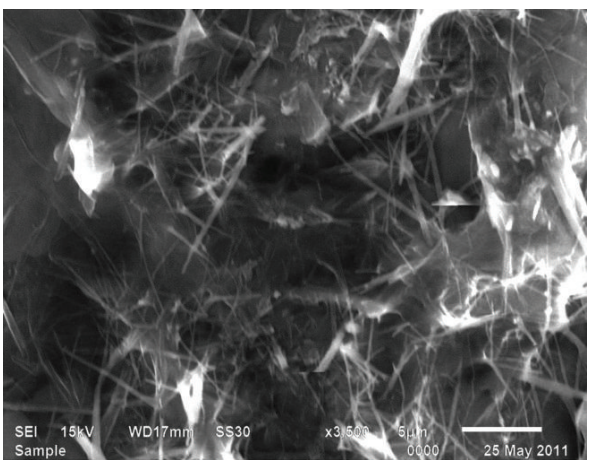

(a)

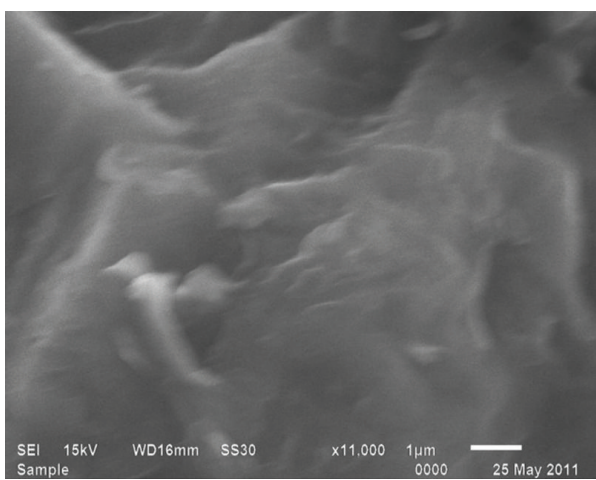

(c)

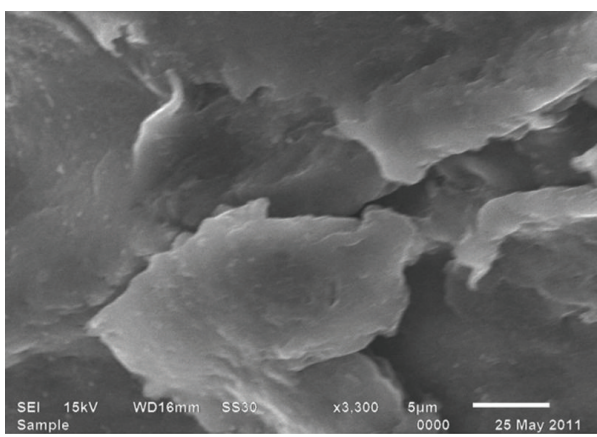

(e)

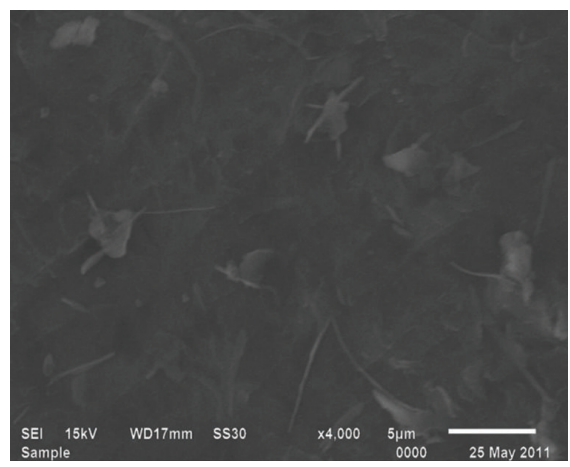

(b)

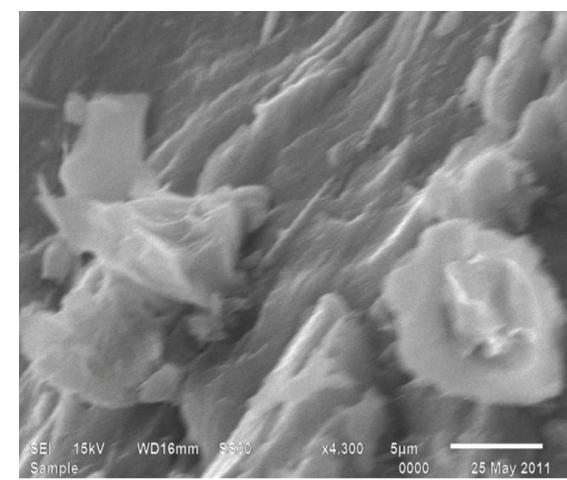

(d)

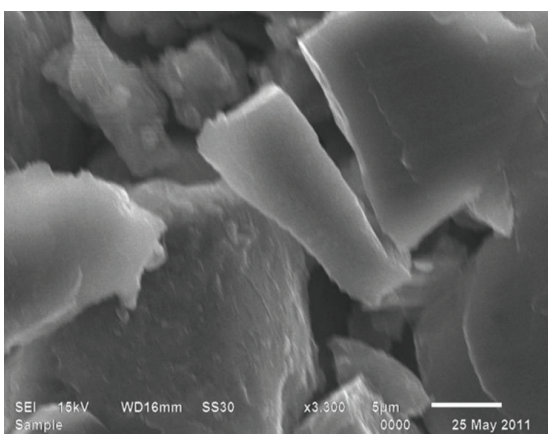

(f)

FIGURE 2: SEM micrographs of (a) polyaniline (PANI), (b) PANI/60\% ZnO-SF-MW, (c) PANI/60\% ZnO-SLS-MW, (d) PANI/40\% ZnO-SLSUP, (e) PANI/60\% ZnO-SLS-UV, and (f) PANI/40\% ZnO-SLS-RT nanocomposites.

nanocomposite. In Figures 4(d) and 4(e), a broad peak occurs at $3435.77 \mathrm{~cm}^{-1}$ and $3435.39 \mathrm{~cm}^{-1}$, respectively. This belongs to $\mathrm{N}-\mathrm{H}$ stretching mode. A weak peak of $-\mathrm{CH}_{2}$ stretching occurs at $2924.36 \mathrm{~cm}^{-1}$. This occurs as a sharp peak at $2920.66 \mathrm{~cm}^{-1}$ in Figure 4(e). The other peaks occurring in Figure 4(a) at $3054.38 \mathrm{~cm}^{-1}, 1573.8 \mathrm{~cm}^{-1}$, and $517 \mathrm{~cm}^{-1}$ have vanished in the spectrum of Figure $4(\mathrm{~d}) . \mathrm{NH}_{2}$ wagging occurs as a very weak peak at $693.40 \mathrm{~cm}^{-1}$. In Figure $4(\mathrm{f})$, there is a shift in the $\mathrm{N}-\mathrm{H}$ stretching mode to lower frequency (very weak band at $3413.81 \mathrm{~cm}^{-1}$ ). C=C stretching of quinoid has moved to $1560.84 \mathrm{~cm}^{-1}$ whereas, for benzenoid ring, the stretching frequency is at $1486.80 \mathrm{~cm}^{-1}$ as compared to that in Figure 4(a). Thus, the above spectra (Figures 4(b)-4(f)) confirm the formation of PANI/ZnO nanocomposites [33].
3.1.5. UV-Visible (UV-VIS) Studies. Figures 5(a) and 5(b) represent the UV-VIS absorption spectra of the synthesized polyaniline (PANI) and polyaniline (PANI)/ZnO nanocomposites. In Figure 5(a), polyaniline (PANI) exhibits two broad absorption peaks at $253.2 \mathrm{~nm}$ and $379.2 \mathrm{~nm}$. This peak corresponds to the $\pi-\pi^{*}$ transition of the benzenoid ring and constitutes the typical emeraldine salt spectrum. A little red shift was observed for the nanocomposites containing $60 \% \mathrm{ZnO}$ nanostructures (synthesized in the absence and presence of surfactant SLS under microwave) and $40 \%$ $\mathrm{ZnO}$ nanostructures (synthesized using SLS under pressure), respectively. This red shift was due to the interaction of polyaniline with $\mathrm{ZnO}$. In the absorption spectrum of nanocomposite containing $60 \% \mathrm{ZnO}$ nanostructures (synthesized 


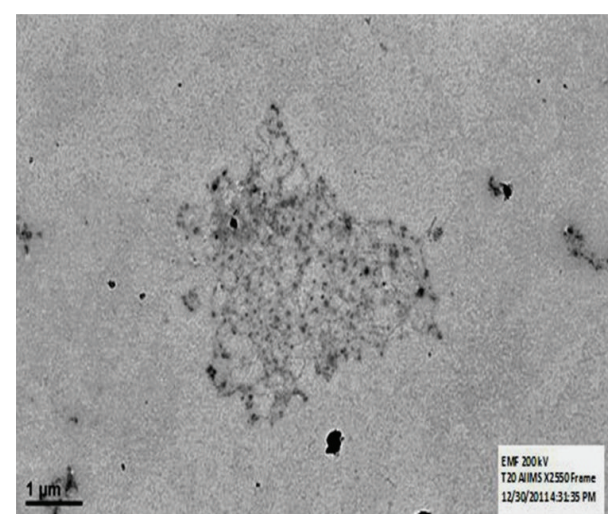

(a)

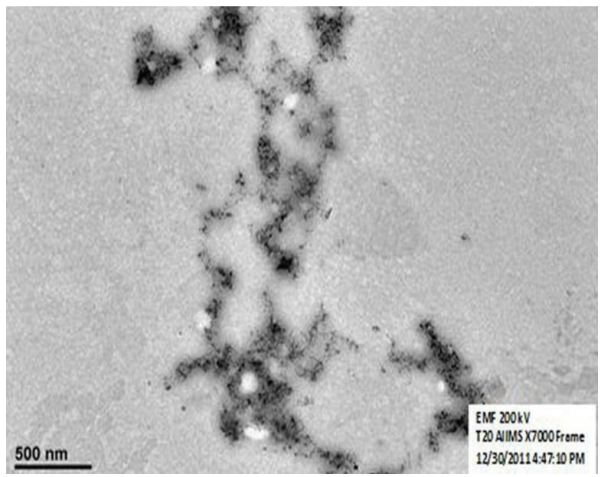

(c)

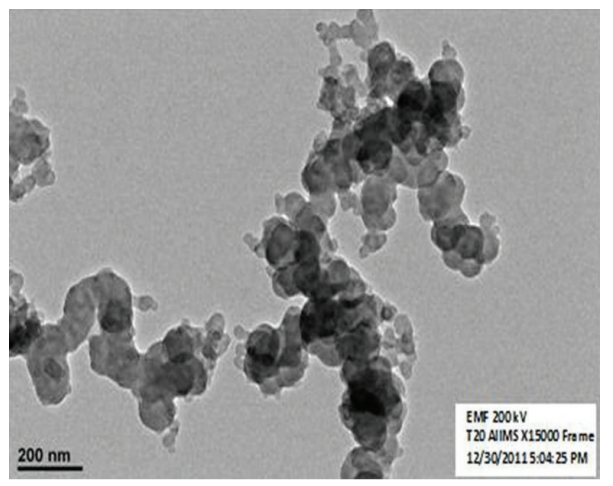

(e)

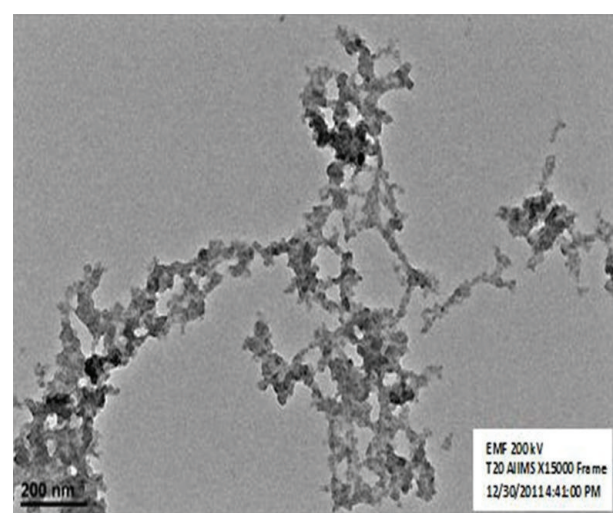

(b)

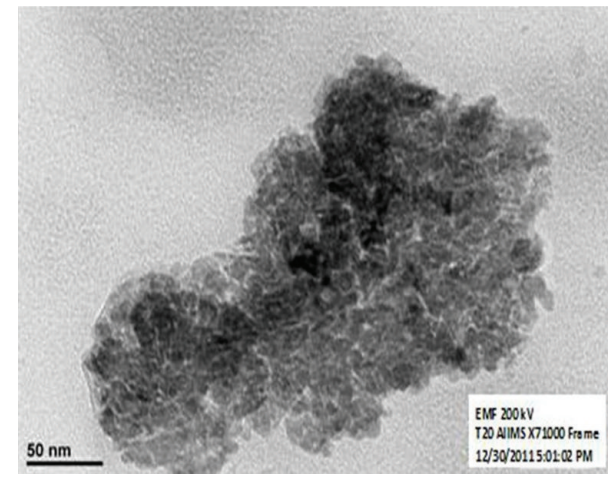

(d)

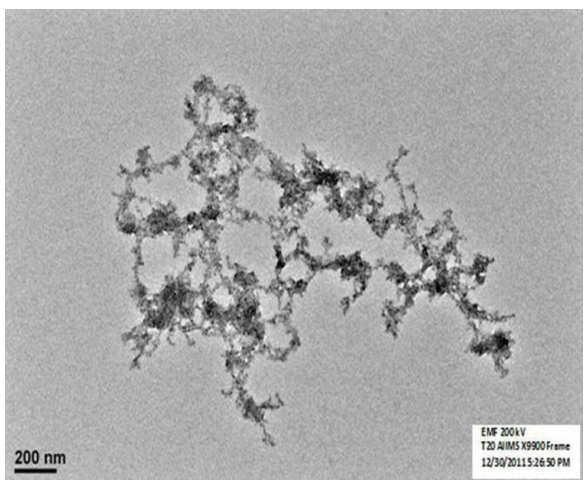

(f)

Figure 3: TEM images of (a) polyaniline (PANI), (b) PANI/60\% ZnO-SF-MW, (c) PANI/60\% ZnO-SLS-MW, (d) PANI/40\% ZnO-SLS-UP, (e) PANI/60\% ZnO-SLS-UV, and (f) PANI/40\% ZnO-SLS-RT nanocomposites.

using SLS under vacuum), a large red shift was observed and the broad peaks appeared at $298.0 \mathrm{~nm}, 342.7 \mathrm{~nm}$, and $776.8 \mathrm{~nm}$. The peak at $776.8 \mathrm{~nm}$ could be assigned to the polaron band transitions. The appearance of this peak in the absorption spectra showed that the polymer chains which have coiled conformation (less conjugation) in chloroform extended causing dispersion and strong interaction between adjacent polarons. Also, it was confirmed that in this case there was strong interaction of $\mathrm{ZnO}$ nanoparticles with the polyaniline. Similarly, in Figure 5(b), a large red shift was observed and a broad peak appeared at $821.0 \mathrm{~nm}$ in addition to two other peaks.
The band gap energy $\left(E_{g}\right)$ of the nanocomposites was determined by substituting the value of the absorption peak at a given wavelength in the following equation [36]:

$$
E_{g}=h v_{g}=\frac{h c}{\lambda_{g}},
$$

where $h=4.14 \times 10^{-15} \mathrm{eVs} ; c=2.99 \times 10^{8} \mathrm{~m} / \mathrm{s} ; \lambda_{g}$ is the wavelength at maximum absorption of each nanocomposite. The $E_{g}$ values have been reported in the Table 2 . The blue shift was observed in the case of PANI/ZnO nanocomposites as compared to $\mathrm{ZnO}$ nanostructures. As the content of $\mathrm{ZnO}$ nanostructures was increased in the polymer matrix, there 


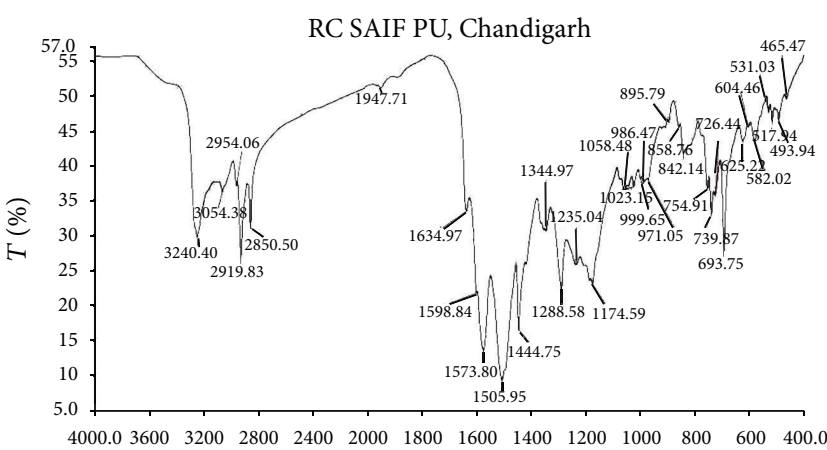

$\left(\mathrm{cm}^{-1}\right)$

(a)

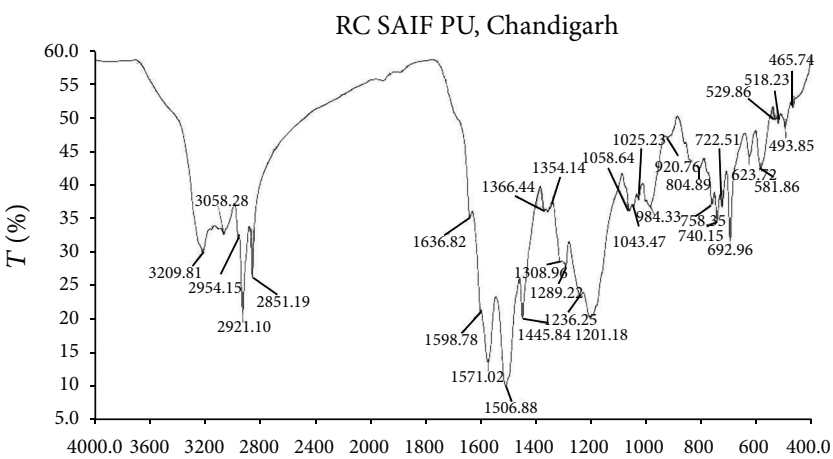
$\left(\mathrm{cm}^{-1}\right)$

(c)

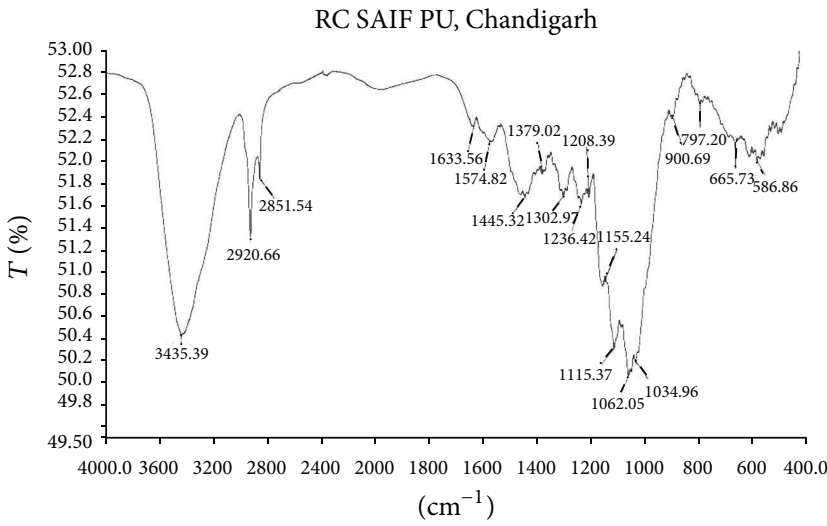

(e)

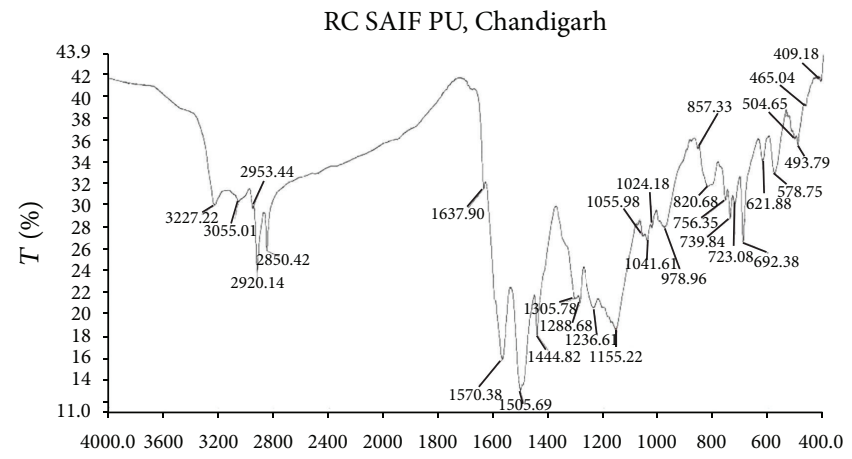

$\left(\mathrm{cm}^{-1}\right)$

(b)

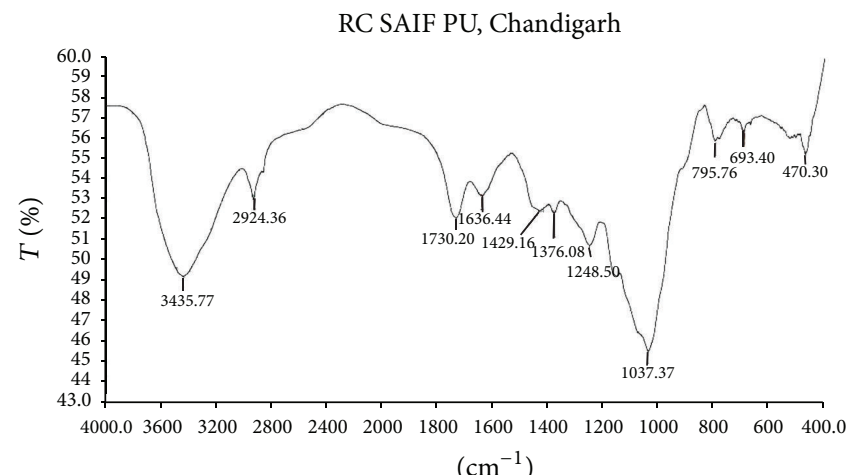

(d)

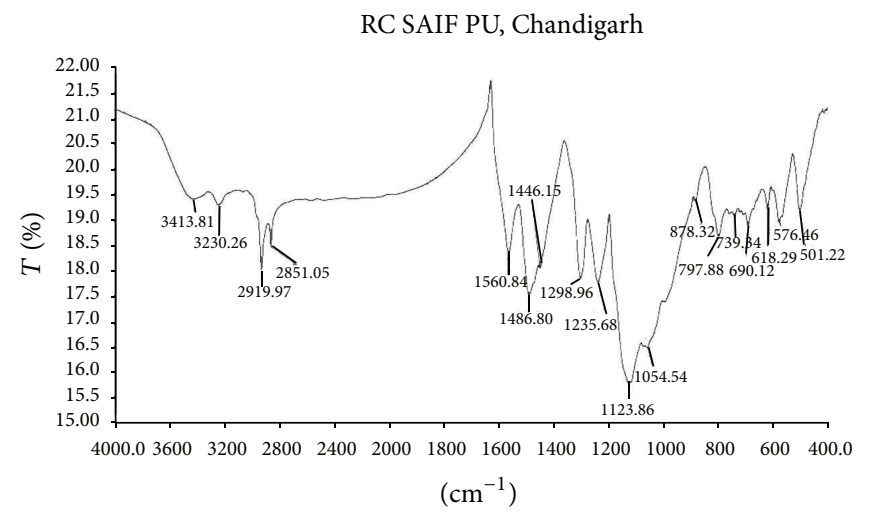

(f)

Figure 4: FTIR spectra of (a) polyaniline (PANI), (b) PANI/60\% ZnO-SF-MW, (c) PANI/60\% ZnO-SLS-MW, (d) PANI/40\% ZnO-SLS-UP, (e) PANI/60\% ZnO-SLS-UV, and (f) PANI/40\% ZnO-SLS-RT nanocomposites.

TABLE 2: Band gap energy of $\mathrm{ZnO}$ nanoparticles and PANI/ZnO nanocomposites.

\begin{tabular}{lcccc}
\hline Sample & $\begin{array}{c}\text { Morphology } \\
\text { of ZnO nps }\end{array}$ & $\begin{array}{c}\text { Size (avg. Dia nm) or length } \\
(\mathrm{nm}) d_{\mathrm{TEM}}, \mathrm{ZnO} \mathrm{nps}\end{array}$ & $\begin{array}{c}\text { Band gap energy of } \\
\text { ZnO nps (eV) }\end{array}$ & $\begin{array}{c}\text { Band gap energy of PANI/ZnO } \\
\text { nanocomposite }(\mathrm{eV})\end{array}$ \\
\hline PANI & - & - & - & 3.26 \\
PANI/60\% ZnO-SF-MW & Spherical & $10-15 \mathrm{~nm}$ & 3.61 & 3.21 \\
PANI/60\% ZnO-SLS-MW & Nanorods & $L=90 \mathrm{~nm}$ & 3.48 & 3.09 \\
PANI/40\% ZnO-SLS-UP & Nanoflowers & Dia $=12-15 \mathrm{~nm}, L=120 \mathrm{~nm}$ & 3.61 & 2.94 \\
PANI/60\% ZnO-SLS-UV & Nanoplates & Dia $=20 \mathrm{~nm}, L=150 \mathrm{~nm}$ & 3.48 & 1.59 \\
PANI/40\% ZnO-SLS-RT & Nanoneedles & Dia $=10-12 \mathrm{~nm}, L=120 \mathrm{~nm}$ & 3.48 & 1.50 \\
\hline
\end{tabular}




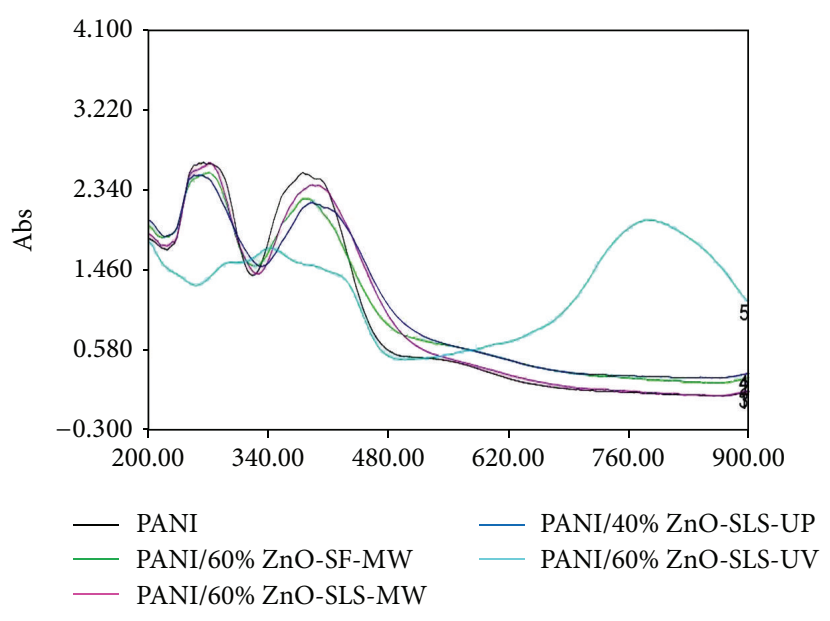

(a)

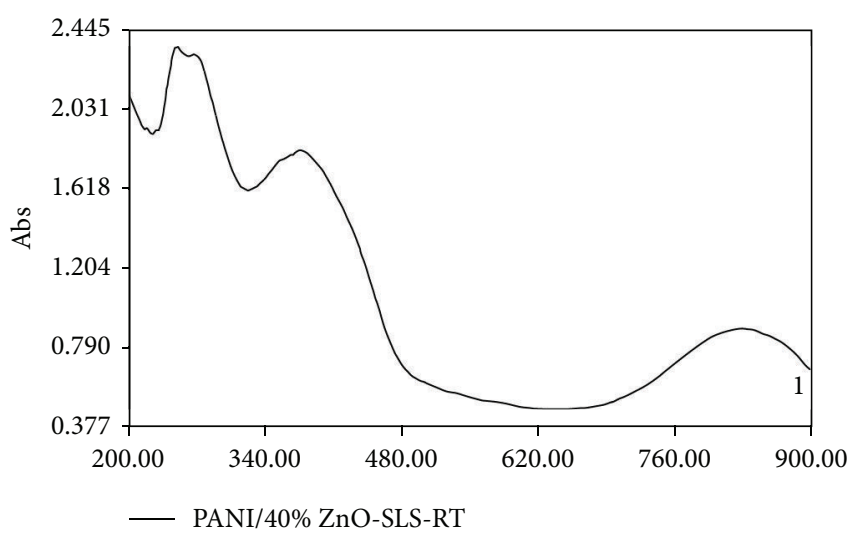

(b)

FIgURE 5: (a) UV-visible spectra of PANI and PANI/ZnO nanocomposites in chloroform. (b) UV-visible spectrum of PANI/ZnO nanocomposite in chloroform.

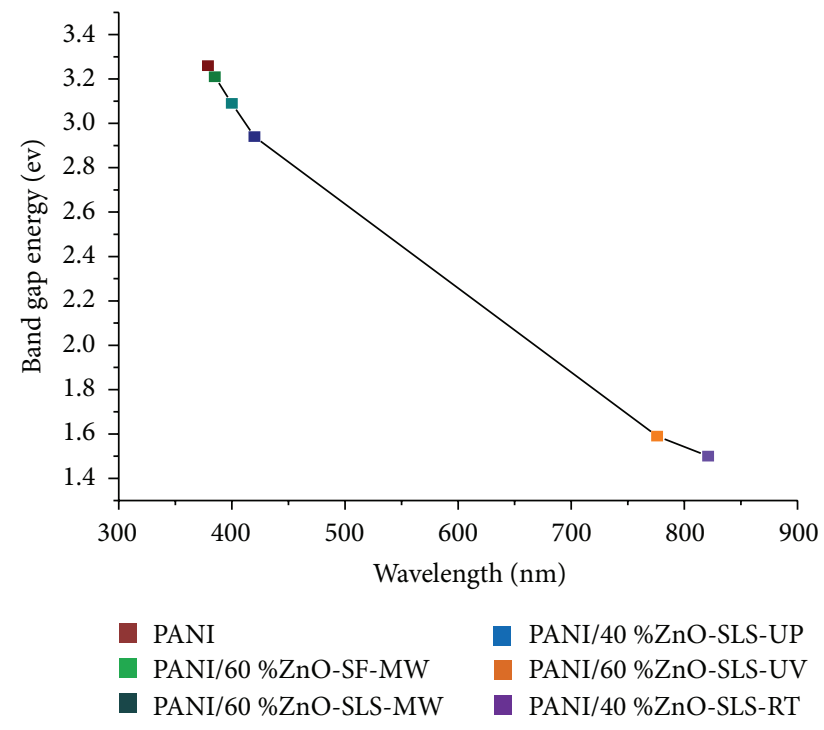

FIGURE 6: Variation of optical band gap energy $\left(E_{g}\right)$ with wavelength at maximum absorption $\left(\lambda_{g}\right)$ of nanocomposites.

was a red shift. This was noticed in PANI $/ 60 \% \mathrm{ZnO}-\mathrm{SF}-$ MW, PANI $/ 60 \%$ ZnO-SLS-MW, and PANI $/ 40 \%$ ZnO-SLSUP. Similar result was observed in PANI/60\% ZnO-SLS-UV and PANI/40\% ZnO-SLS-RT. Thus, the optical band gap energy is found to be dependent on the composition of nanocomposites [37].

Further, it was observed that, with increase in the wavelength at maximum absorption, the band gap energy $\left(E_{g}\right)$ values decreased (Figure 6).

3.2. Conductivity Measurement. The conductivities of assynthesized polyaniline and $\mathrm{PANI} / \mathrm{ZnO}$ nanocomposites with different amounts of $\mathrm{ZnO}$ nanostructures were measured by two-probe method. The results indicated that, as the content of the $\mathrm{ZnO}$ nanostructures was increased, the conductivity of the nanocomposite increased as compared with that of polyaniline. $20 \%$ to $80 \%$ of the initial weight of $\mathrm{ZnO}$ nanostructures synthesized in absence and presence of surfactant (sodium lauryl sulphate, SLS) under different reaction conditions were taken. All the measurements were done at room temperature $\left(30^{\circ} \mathrm{C}\right)$ at an applied voltage of 20 volts. Measurements were taken after $15 \mathrm{~min}$ of applying voltage.

In two-probe instrument, electrodes were of $\mathrm{Al}$ foil of thickness $1 \mathrm{~mm}$ and area $1 \mathrm{~cm}^{2}$.

Conductivity $\left(\sigma_{\mathrm{dc}}\right)$ was calculated using the following formula:

$$
\sigma_{\mathrm{dc}}=\frac{l}{R a},
$$

where $l$ is the sample thickness (thickness of the pellet); $R$ is the resistance; $a$ is the cross-sectional area of electrode.

Conductivity data of polyaniline/ $\mathrm{ZnO}$ nanocomposites has been presented in Table 3 .

The results indicated that, as the content of the $\mathrm{ZnO}$ nanostructures was increased, the conductivity of the nanocomposite increased as compared with that of polyaniline. The addition of $\mathrm{ZnO}$ nanostructures in the polmer matric enhanced the conductivity of the polymer.

The conductivity was found to increase with the embedment of PANI with $\mathrm{ZnO}$ nanostructures. Initially, with increase in weight $\%$ of $\mathrm{ZnO}$ nanostructures, the conductivity of nanocomposites was found to increase. However, after reaching the maximum conductivity with optimum $\mathrm{ZnO}$ nanostructure concentration, further increase in $\mathrm{ZnO}$ nanoparticles resulted in decreased conductivity. This can be explained on the basis that high concentration of $\mathrm{ZnO}$ nanoparticles hinders the carrier transport between the different conjugated chains of polyaniline (PANI) [38]. The existence of interaction between PANI and $\mathrm{ZnO}$ nanostructures leads to the reduction of the conjugated lengths in 
TABLE 3: Conductivity data of polyaniline/ZnO nanocomposites.

\begin{tabular}{|c|c|c|c|c|c|c|}
\hline S. no. & Sample & $\% \mathrm{ZnO}$ NPS & $\begin{array}{c}\text { Current }(I) \text {, } \\
\text { amperes }\end{array}$ & $\begin{array}{l}\text { Resistance } \\
\text { (R), OHM }\end{array}$ & $\begin{array}{c}\text { Sample } \\
\text { thickness }(l), \mathrm{cm}\end{array}$ & $\sigma_{\mathrm{dc}}, S / \mathrm{cm}$ \\
\hline 1 & PANI & - & $8 * 10^{-12}$ & $2.5 * 10^{12}$ & 0.088 & $4.5 * 10^{-14}$ \\
\hline 2 & PANI/ZnO (in absence of surfactant) & 20 & $9 * 10^{-12}$ & $2.22 * 10^{12}$ & 0.093 & $5.3 * 10^{-14}$ \\
\hline 3 & PANI/ZnO (in absence of surfactant) & 40 & $18 * 10^{-12}$ & $1.11 * 10^{12}$ & 0.147 & $1.6 * 10^{-13}$ \\
\hline 4 & PANI/ZnO (in absence of surfactant) & 60 & $15 * 10^{-12}$ & $1.33 * 10^{12}$ & 0.191 & $1.82 * 10^{-13}$ \\
\hline 5 & PANI/ZnO (in absence of surfactant) & 80 & $7 * 10^{-12}$ & $2.85 * 10^{12}$ & 0.004 & $1.79 * 10^{-15}$ \\
\hline 6 & $\begin{array}{l}\mathrm{PANI} / \mathrm{ZnO} \text { (in presence of surfactant, SLS, } \\
\text { under microwave) }\end{array}$ & 20 & $25 * 10^{-12}$ & $0.80 * 10^{12}$ & 0.195 & $3.1 * 10^{-13}$ \\
\hline 7 & $\begin{array}{l}\mathrm{PANI} / \mathrm{ZnO} \text { (in presence of surfactant, SLS, } \\
\text { under microwave) }\end{array}$ & 40 & $21 * 10^{-12}$ & $0.95 * 10^{12}$ & 0.109 & $1.46 * 10^{-13}$ \\
\hline 8 & $\begin{array}{l}\mathrm{PANI} / \mathrm{ZnO} \text { (in presence of surfactant, SLS, } \\
\text { under microwave) }\end{array}$ & 60 & $35.2 * 10^{-12}$ & $0.57 * 10^{12}$ & 0.19 & $4.2 * 10^{-13}$ \\
\hline 9 & $\begin{array}{l}\mathrm{PANI} / \mathrm{ZnO} \text { (in presence of surfactant, SLS, } \\
\text { under microwave) }\end{array}$ & 80 & $5 * 10^{-12}$ & $4.0 * 10^{12}$ & 0.143 & $4.55 * 10^{-14}$ \\
\hline 10 & $\begin{array}{l}\mathrm{PANI} / \mathrm{ZnO} \text { (in presence of surfactant, SLS, } \\
\text { under pressure) }\end{array}$ & 20 & $11 * 10^{-12}$ & $1.82 * 10^{12}$ & 0.129 & $9.1 * 10^{-14}$ \\
\hline 11 & $\begin{array}{l}\mathrm{PANI} / \mathrm{ZnO} \text { (in presence of surfactant, SLS, } \\
\text { under pressure) }\end{array}$ & 40 & $10 * 10^{-12}$ & $2.0 * 10^{12}$ & 0.181 & $1.15 * 10^{-13}$ \\
\hline 12 & $\begin{array}{l}\mathrm{PANI} / \mathrm{ZnO} \text { (in presence of surfactant, SLS, } \\
\text { under pressure) }\end{array}$ & 60 & $6 * 10^{-12}$ & $3.33 * 10^{12}$ & 0.180 & $6.9 * 10^{-14}$ \\
\hline 13 & $\begin{array}{l}\mathrm{PANI} / \mathrm{ZnO} \text { (in presence of surfactant, SLS, } \\
\text { under pressure) }\end{array}$ & 80 & $4 * 10^{-12}$ & $5.0 * 10^{12}$ & 0.150 & $3.8 * 10^{-14}$ \\
\hline 14 & $\begin{array}{l}\mathrm{PANI} / \mathrm{ZnO} \text { (in presence of surfactant, SLS, } \\
\text { under vacuum) }\end{array}$ & 20 & $16 * 10^{-12}$ & $1.25 * 10^{12}$ & 0.115 & $1.17 * 10^{-13}$ \\
\hline 15 & $\begin{array}{l}\text { PANI/ZnO (in presence of surfactant, SLS, } \\
\text { under vacuum) }\end{array}$ & 40 & $11 * 10^{-12}$ & $1.81 * 10^{12}$ & 0.199 & $1.40 * 10^{-13}$ \\
\hline 16 & $\begin{array}{l}\mathrm{PANI} / \mathrm{ZnO} \text { (in presence of surfactant, SLS, } \\
\text { under vacuum) }\end{array}$ & 60 & $24 * 10^{-12}$ & $0.833 * 10^{12}$ & 0.194 & $2.9 * 10^{-13}$ \\
\hline 17 & $\begin{array}{l}\text { PANI/ZnO (in presence of surfactant, SLS, } \\
\text { under vacuum) }\end{array}$ & 80 & $18 * 10^{-12}$ & $1.11 * 10^{12}$ & 0.114 & $1.3 * 10^{-13}$ \\
\hline 18 & $\begin{array}{l}\text { PANI/ZnO (in presence of surfactant, SLS, } \\
\text { at room temperature) }\end{array}$ & 20 & $9 * 10^{-12}$ & $2.22 * 10^{12}$ & 0.150 & $8.6 * 10^{-14}$ \\
\hline 19 & $\begin{array}{l}\mathrm{PANI} / \mathrm{ZnO} \text { (in presence of surfactant, SLS, } \\
\text { at room temperature) }\end{array}$ & 40 & $13 * 10^{-12}$ & $1.53 * 10^{12}$ & 0.249 & $2.07 * 10^{-13}$ \\
\hline 20 & $\begin{array}{l}\text { PANI/ZnO (in presence of surfactant, SLS, } \\
\text { at room temperature) }\end{array}$ & 60 & $9 * 10^{-12}$ & $2.22 * 10^{12}$ & 0.10 & $5.7 * 10^{-14}$ \\
\hline 21 & $\begin{array}{l}\mathrm{PANI} / \mathrm{ZnO} \text { (in presence of surfactant, SLS, } \\
\text { at room temperature) }\end{array}$ & 80 & $8 * 10^{-12}$ & $2.5 * 10^{12}$ & 0.11 & $5.6 * 10^{-14}$ \\
\hline
\end{tabular}

the PANI chains. It has been observed that, in most of the cases, embedment of $60 \% \mathrm{ZnO}$ nanostructures in the PANI matrix gave optimum conductivity values. The order of the conductivity found was

PANI/ZnO-SLS-MW > PANI/ZnO-SLS-UV > PANI/ ZnO-SF-MW > ZnO-SLS-UP > PANI/ZnO-SLS-RT.

\section{Conclusion}

PANI/ZnO nanocomposites were synthesized via in situ oxidative polymerization of aniline monomer. Different weights of $\mathrm{ZnO}$ nanostructures prepared in the absence and presence of surfactant were added to the aniline prior to polymerization. The surface morphology changed with the addition of $\mathrm{ZnO}$ nanostructures. This is well evident from the SEM images of the nanocomposites. The surfactant sodium lauryl sulphate (SLS) was added to the aniline solution. This acted as a stabilizer and contained amine group which was grafted on the growing polymer (PANI) chains. Moreover, it assured a good dispersion of $\mathrm{ZnO}$ nanoparticles in the PANI matrix along with embedding them in the polymer chains. The surfactant also promotes the micelle formation and oxidation reaction. This is well represented in the FTIR spectra of polyaniline and nanocomposites. The UV-visible spectra demonstrated the shifting and change in the intensity of the peaks which confirmed the effective interaction of $\mathrm{ZnO}$ nanostructures with the polyaniline through the hydrogen bonding between the imine group $(-\mathrm{NH})$ of 
PANI and hydroxyl (-OH) group of $\mathrm{ZnO}$ nanostructures. The calculated optical band gap energy values of nanocomposites were found to be dependent on the weight percent of $\mathrm{ZnO}$ nanostructures embedded in the polymer matrix. The observations show that PANI/ZnO nanocomposites can be used potentially in molecular electronics and optical devises. It was concluded that the conductivity of $\mathrm{ZnO}$ nanocomposites initially increased and then decreased with the increase in the content of $\mathrm{ZnO}$ nanostructures due to the fact that increased \% of $\mathrm{ZnO}$ nanostructures hinders the carrier transport between the different conjugated chains of polyaniline (PANI).

\section{Conflict of Interests}

I hereby state that authors of this manuscript including me do not have any conflict of interests regarding the publication of this paper.

\section{References}

[1] X. Ma, X. Zhang, Y. Li et al., "Preparation of nano-structured polyaniline composite film via "carbon nanotubes seeding" approach and its gas-response studies," Macromolecular Materials and Engineering, vol. 291, no. 1, pp. 75-82, 2006.

[2] S. Ameen, M. S. Akhtar, Y. S. Kim, O. Yang, and H. Shin, "An effective nanocomposite of polyaniline and $\mathrm{ZnO}$ : preparation, characterizations, and its photocatalytic activity," Colloid and Polymer Science, vol. 289, no. 4, pp. 415-421, 2011.

[3] E. Tang, G. Cheng, and X. Ma, "Preparation of nano- $\mathrm{ZnO} /$ PMMA composite particles via grafting of the copolymer onto the surface of zinc oxide nanoparticles," Powder Technology, vol. 161, no. 3, pp. 209-214, 2006.

[4] A. P. O'Mullane, S. E. Dale, J. V. Macpherson, and P. R. Unwin, "Fabrication and electrocatalytic properties of polyaniline/Pt nanoparticle composites," Chemical Communications, vol. 10, no. 14, pp. 1606-1607, 2004.

[5] P. S. Hale, L. M. Maddox, J. G. Shapter, N. H. Voelcker, M. J. Ford, and E. R. Waclawik, "Growth kinetics and modeling of znO nanoparticles," Journal of Chemical Education, vol. 82, no. 5, pp. 775-778, 2005.

[6] D. Segets, J. Gradl, R. K. Taylor, V. Vassilev, and W. Peukert, "Analysis of optical absorbance spectra for the determination of $\mathrm{ZnO}$ nanoparticle size distribution, solubility, and surface energy," ACS Nano, vol. 3, no. 7, pp. 1703-1710, 2009.

[7] S. T. Tan, B. J. Chen, X. W. Sun et al., "Blueshift of optical band gap in $\mathrm{ZnO}$ thin films grown by metal-organic chemical-vapor deposition," Journal of Applied Physics, vol. 98, no. 1, Article ID 013505, 2005.

[8] S. Gao, H. Zhang, X. Wang, R. Deng, D. Sun, and G. Zheng, "ZnO-based hollow microspheres: biopolymer-assisted assemblies from ZnO nanorods," Journal of Physical Chemistry B, vol. 110, no. 32, pp. 15847-15852, 2006.

[9] A. V. Chadwick, N. V. Russell, A. R. Whitham, and A. Wilson, "Nanocrystalline metal oxide gas sensors," Sensors and Actuators B, vol. 18, no. 1-3, pp. 99-102, 1994.

[10] H. T. Wang, B. S. Kang, F. Ren et al., "Hydrogen-selective sensing at room temperature with $\mathrm{ZnO}$ nanorods," Applied Physics Letters, vol. 86, no. 24, pp. 1243501-3243503, 2005.
[11] P. D. Batista and M. Mulato, " $\mathrm{ZnO}$ extended-gate field-effect transistors as pH sensors," Applied Physics Letters, vol. 87, no. 14, pp. 1435081-1435083, 2005.

[12] S. Hashimoto and A. Yamaguchi, "Growth morphology and mechanism of a hollow $\mathrm{ZnO}$ polycrystal," Journal of the American Ceramic Society, vol. 79, no. 4, pp. 1121-1123, 1996.

[13] X. Y. Kong, Y. Ding, R. Yang, and Z. L. Wang, "Single-crystal nanorings formed by epitaxial self-coiling of polar nanobelts," Science, vol. 303, no. 5662, pp. 1348-1351, 2004.

[14] Z. W. Pan, Z. R. Dai, and Z. L. Wang, "Nanobelts of semiconducting oxides," Science, vol. 291, no. 5510, pp. 1947-1949, 2001.

[15] E. Comini, G. Faglia, G. Sberveglieri, Z. Pan, and Z. L. Wang, "Stable and highly sensitive gas sensors based on semiconducting oxide nanobelts," Applied Physics Letters, vol. 81, no. 10, pp. 1869-1871, 2002

[16] A. Sekar, S. H. Kim, A. Umar, and Y. B. Hahn, "Catalyst-free synthesis of $\mathrm{ZnO}$ nanowires on $\mathrm{Si}$ by oxidation of $\mathrm{Zn}$ powders," Journal of Crystal Growth, vol. 277, no. 1-4, pp. 471-478, 2005.

[17] P. X. Gao and Z. L. Wang, "Mesoporous polyhedral cages and shells formed by textured self-assembly of $\mathrm{ZnO}$ nanocrystals," Journal of the American Chemical Society, vol. 125, no. 37, pp. 11299-11305, 2003.

[18] Z. L. Wang, "Novel zinc oxide nanostructures discovery by electron microscopy," Journal of Physics, vol. 26, no. 1, pp. 1-6, 2006.

[19] J. Huang, C. Xia, L. Cao, and X. Zeng, "Facile microwave hydrothermal synthesis of zinc oxide one-dimensional nanostructure with three-dimensional morphology," Materials Science and Engineering B, vol. 150, no. 3, pp. 187-193, 2008.

[20] W. Bai, K. Yu, Q. Zhang et al., "Large-scale synthesis of zinc oxide rose-like structures and their optical properties," Physica E, vol. 40, no. 4, pp. 822-827, 2008.

[21] M. G. Han, S. K. Cho, S. G. Oh, and S. S. Im, "Preparation and characterization of polyaniline nanoparticles synthesized from DBSA micellar solution," Synthetic Metals, vol. 126, no. 1, pp. 5360, 2002.

[22] W. Yin and E. Ruckenstein, "Soluble polyaniline co-doped with dodecyl benzene sulfonic acid and hydrochloric acid," Synthetic Metals, vol. 108, no. 1, pp. 39-46, 2000.

[23] R. Ansari, "Application of polyaniline and its composites for adsorption/recovery of chromium (VI) from aqueous solutions," Acta Chimica Slovenica, vol. 53, no. 1, pp. 88-94, 2006.

[24] W. J. Feast, J. Tsibouklis, K. L. Pouwer, L. Groenendaal, and E. W. Meijer, "Synthesis, processing and material properties of conjugated polymers," Polymer, vol. 37, no. 22, pp. 5017-5047, 1996.

[25] W. S. Huang, B. D. Humphrey, and A. G. MacDiarmid, "Polyaniline, a novel conducting polymer. Morphology and chemistry of its oxidation and reduction in aqueous electrolytes," Journal of the Chemical Society Faraday Transactions, vol. 82, no. 8, pp. 2385-2400, 1986.

[26] R. Ansari and M. B. Keivani, "Polyaniline conducting electroactive polymers: thermal and environmental stability studies," $E$ Journal of Chemistry, vol. 3, no. 4, pp. 202-217, 2006.

[27] W. Caseri, "Nanocomposites of polymers and metals or semiconductors: historical background and optical properties," Macromolecular Rapid Communications, vol. 21, no. 11, pp. 705$722,2000$.

[28] E. J. Bourgeat-Lami, "Organic-inorganic nanostructured colloids," Journal of Nanoscience and Nanotechnology, vol. 2, no. 1, pp. 1-24, 2002. 
[29] A. H. Yuwono, B. Liu, J. Xue et al., "Controlling the crystallinity and nonlinear optical properties of transparent $\mathrm{TiO}_{2}-\mathrm{PMMA}$ nanohybrids," Journal of Materials Chemistry, vol. 14, no. 20, pp. 2978-2987, 2004.

[30] A. Okada and A. Usuki, "The chemistry of polymer-clay hybrids," Materials Science and Engineering C, vol. 3, no. 2, pp. 109-115, 1995.

[31] X. D. Zhou and H. C. Gu, "Synthesis of PMMA-ceramics nanocomposites by spray process," Journal of Materials Science Letters, vol. 21, no. 7, pp. 577-580, 2002.

[32] L. L. Hench and J. K. West, "The Sol-Gel process," Chemical Reviews, vol. 90, no. 1, pp. 33-72, 1990.

[33] X. Li and X. Li, "Oxidative polymerization of aniline using $\mathrm{NaClO}_{2}$ as an oxidant," Materials Letters, vol. 61, no. 10, pp. 20112014, 2007.

[34] Y. C. Liu and T. C. Chuang, "Synthesis and characterization of gold/polypyrrole core-shell nanocomposites and elemental gold nanoparticles based on the gold-containing nanocomplexes prepared by electrochemical methods in aqueous solutions," Journal of Physical Chemistry B, vol. 107, no. 45, pp. 12383-12386, 2003.

[35] S. S. Ray, K. Okamoto, and M. Okamoto, "Structure and properties of nanocomposites based on poly(butylene succinate) and organically modified montmorillonite," Journal of Applied Polymer Science, vol. 102, no. 1, pp. 777-785, 2006.

[36] D. Segets, J. Gradl, R. K. Taylor, V. Vassilev, and W. Peukert, "Analysis of optical absorbance spectra for the determination of $\mathrm{ZnO}$ nanoparticle size distribution, solubility, and surface energy," ACS Nano, vol. 3, no. 7, pp. 1703-1710, 2009.

[37] L. Irimpan, V. P. N. Nampoori, and P. Radhakrishnan, "Spectral and nonlinear optical characteristics of nanocomposites of ZnO-CdS," Journal of Applied Physics, vol. 103, no. 9, pp. 094914-094918, 2008.

[38] A. L. Khan and M. Khalid, "Synthesis of nano-sized $\mathrm{ZnO}$ and polyaniline-zinc oxide @omposite: characterization, stability in terms of DC electrical conductivity retention and application in ammonia vapor detection," Journal of Applied Polymer Science, vol. 117, no. 3, pp. 1601-1607, 2010. 

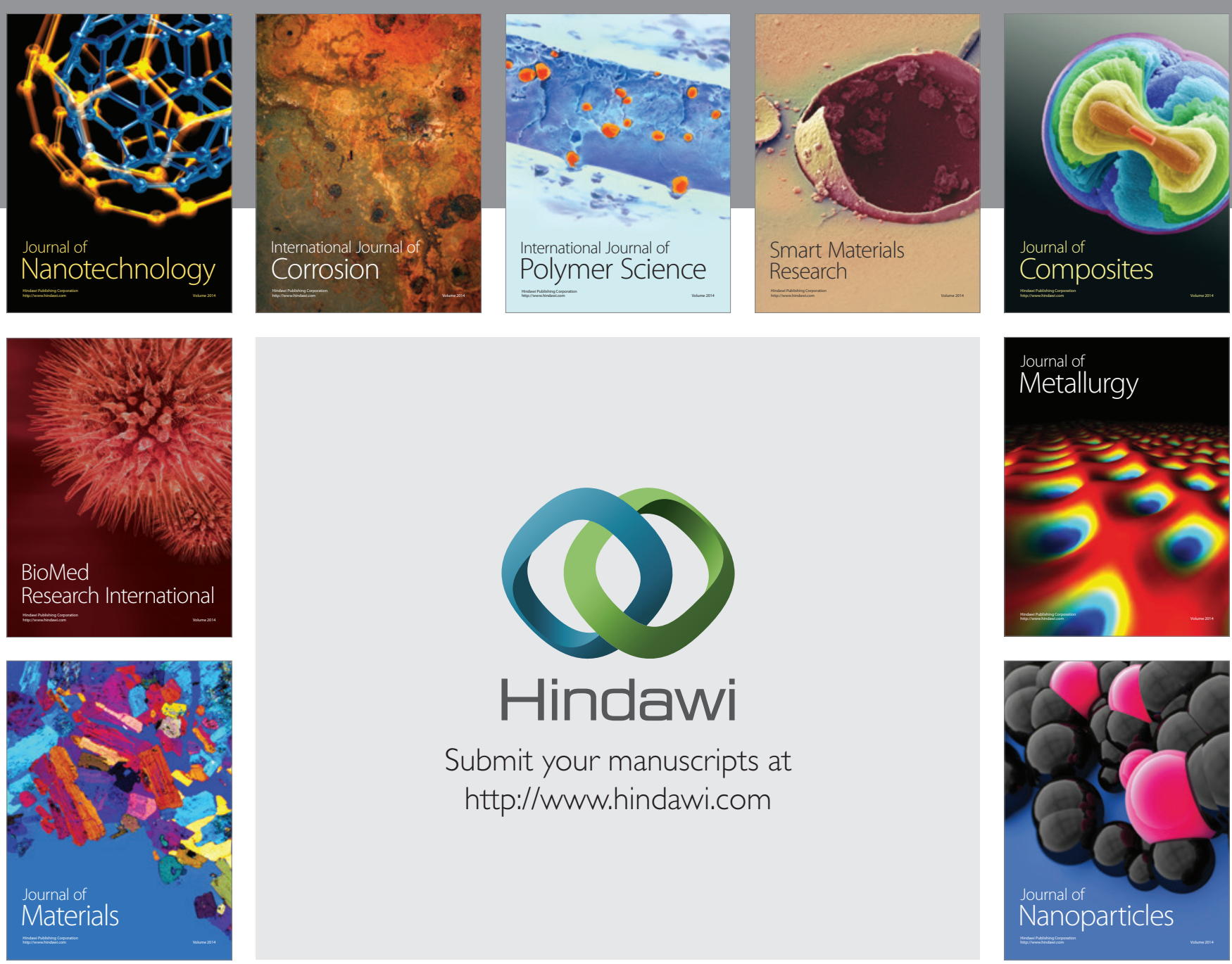

Submit your manuscripts at http://www.hindawi.com
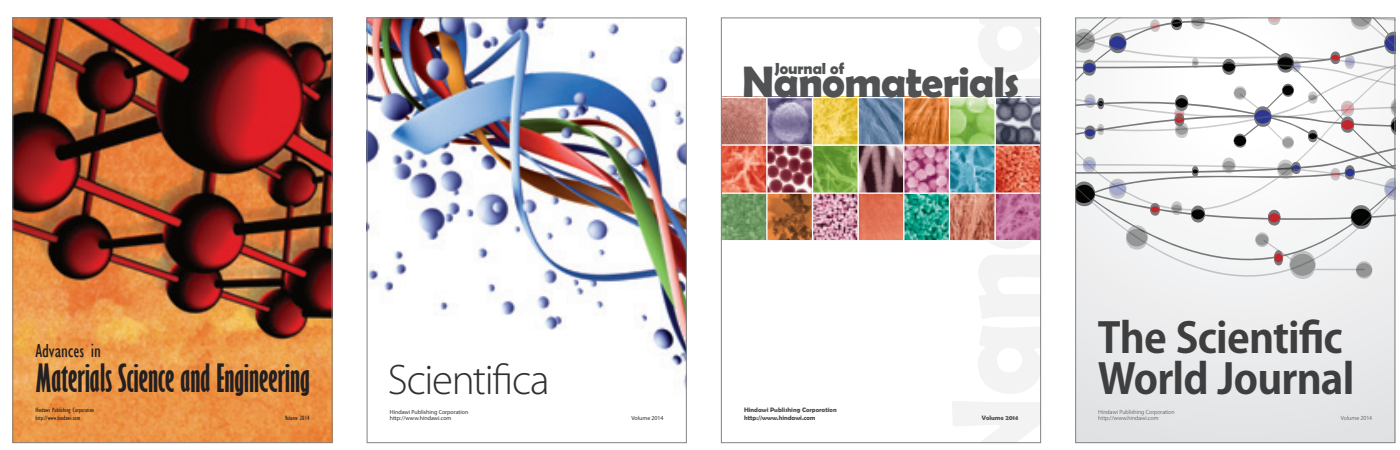

\section{The Scientific World Journal}
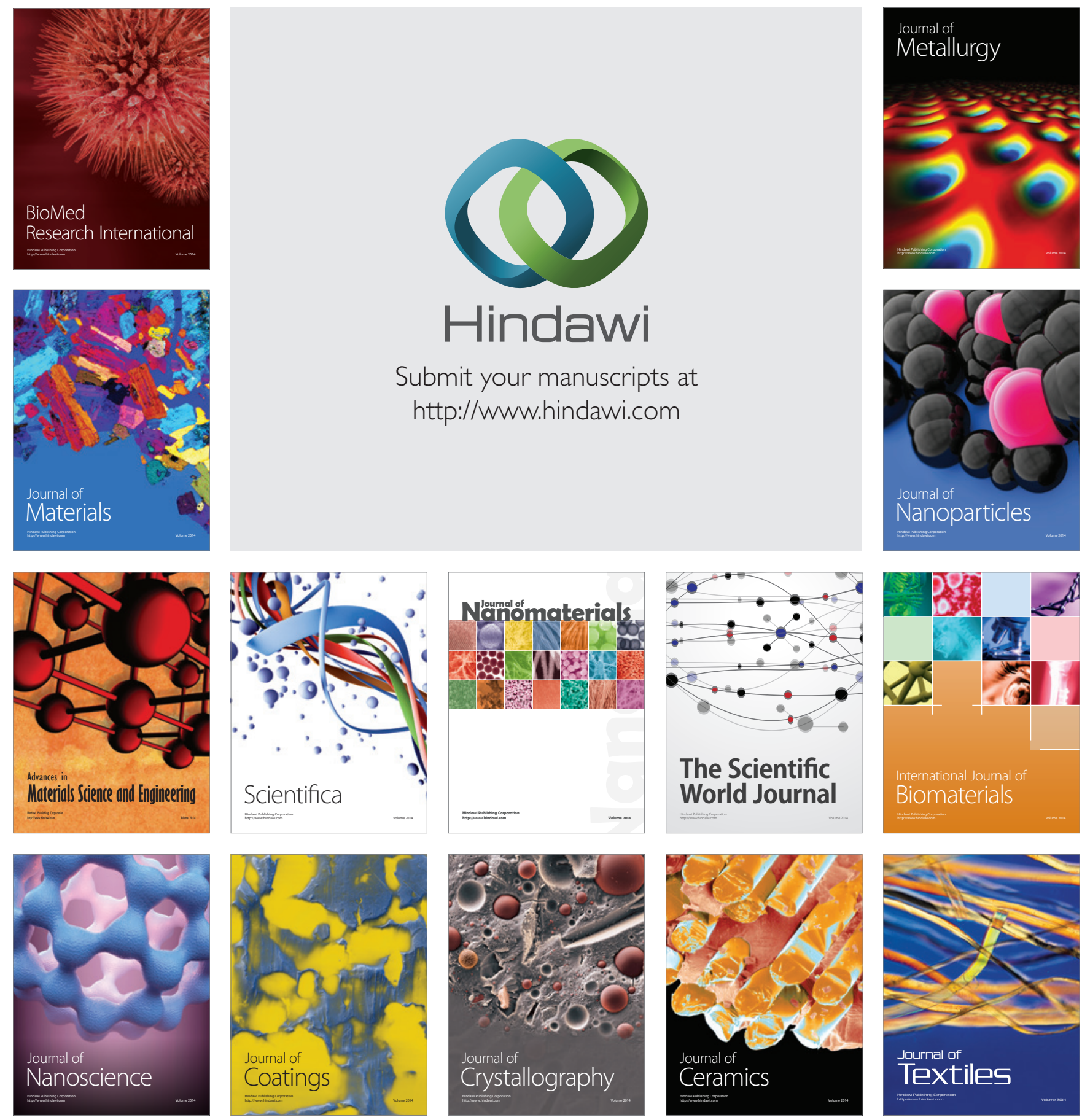